\title{
Enhanced biological fixation of methane for microbial lipid production by recombinant Methylomicrobium buryatense
}

Qiang Fei ${ }^{1,2 *}$, Aaron W. Puri ${ }^{3}$, Holly Smith², Nancy Dowe ${ }^{2}$ and Philip. T. Pienkos ${ }^{2}$

\begin{abstract}
Background: Due to the success of shale gas development in the US, the production cost of natural gas has been reduced significantly, which in turn has made methane $\left(\mathrm{CH}_{4}\right)$, the major component of natural gas, a potential alternative substrate for bioconversion processes compared with other high-price raw material sources or edible feedstocks. Therefore, exploring effective ways to use $\mathrm{CH}_{4}$ for the production of biofuels is attractive. Biological fixation of $\mathrm{CH}_{4}$ by methanotrophic bacteria capable of using $\mathrm{CH}_{4}$ as their sole carbon and energy source has obtained great attention for biofuel production from this resource.

Results: In this study, a fast-growing and lipid-rich methanotroph, Methylomicrobium buryatense 5GB1 and its glycogen-knock-out mutant (AP18) were investigated for the production of lipids derived from intracellular membranes, which are key precursors for the production of green diesel. The effects of culture conditions on cell growth and lipid production were investigated in high cell density cultivation with continuous feeding of $\mathrm{CH}_{4}$ and $\mathrm{O}_{2}$. The highest dry cell weight observed was $21.4 \mathrm{~g} / \mathrm{L}$ and the maximum lipid productivity observed was $45.4 \mathrm{mg} / \mathrm{L} / \mathrm{h}$ obtained in batch cultures, which corresponds to a 2-fold enhancement in cell density and 3-fold improvement in lipid production, compared with previous reported data from cultures of 5GB1. A 90\% enhancement of lipid content was achieved by limiting the biosynthesis of glycogen in strain AP18. Increased $\mathrm{CH}_{4} / \mathrm{O}_{2}$ uptake and $\mathrm{CO}_{2}$ evaluation rates were observed in AP18 cultures suggesting that more carbon substrate and energy are needed for AP18 growth while producing lipids. The lipid produced by M. buryatense was estimated to have a cetane number of 75 , which is $50 \%$ higher than biofuel standards requested by US and EU.

Conclusions: Cell growth and lipid production were significantly influenced by culture conditions for both 5GB1 and AP18. Enhanced lipid production in terms of titer, productivity, and content was achieved under high cell density culture conditions by blocking glycogen accumulation as a carbon sink in the strain AP18. Differences observed in $\mathrm{CH}_{4} /$ $\mathrm{O}_{2}$ gas uptake and $\mathrm{CO}_{2}$ evolution rates as well as cell growth and glycogen accumulation between 5GB1 and AP18 suggest changes in the metabolic network between these strains. This bioconversion process provides a promising opportunity to transform $\mathrm{CH}_{4}$ into biofuel molecules and encourages further investigation to elucidate the remarkable $\mathrm{CH}_{4}$ biofixation mechanism used by these bacteria.
\end{abstract}

Keywords: Methane biofixation, Methanotrophic bacteria, Membrane lipids, High cell density culture, Bioconversion process, Metabolic engineering

\footnotetext{
*Correspondence: feiqiang@xjtu.edu.cn

${ }^{1}$ School of Chemical Engineering and Technology, Xi'an Jiaotong University, Xi'an, China

Full list of author information is available at the end of the article
} 


\section{Background}

Methane $\left(\mathrm{CH}_{4}\right)$ is the simplest and most energy dense alkane with a specific energy of $55 \mathrm{MJ} / \mathrm{kg}$. Only $36 \%$ of $\mathrm{CH}_{4}$ released into the atmosphere is contributed by natural geological activities [1], while most of the rest is due to human activities (Fig. 1), such as energy extraction, agriculture, and waste management [2]. Since 2008, the development of shale gas technologies in the US has reduced the cost of natural gas significantly, making $\mathrm{CH}_{4}$ (the major component of natural gas) a potential alternative carbon source for bioconversion processes compared with other high-price raw material sources or edible feedstocks [3]. However, more than 5.4 quads $(1.47 \times 105$ million cubic meters) of natural gas have been flared annually as a wasted resource at oil production sites around the globe $[4,5]$. Therefore, it is urgent to explore alternative approaches to use $\mathrm{CH}_{4}$ more efficiently and economically. Biological fixation of $\mathrm{CH}_{4}$ by microorganisms has been attracting great attention and is a promising strategy to increase the value of natural gas [6] as well as another major source of $\mathrm{CH}_{4}$, biogas [7].

Methanotrophic bacteria, which were discovered in 1906 [8] and then characterized beginning in the 1970s [9], are a group of bacteria capable of utilizing $\mathrm{CH}_{4}$ as their sole carbon and energy source. Although some methanotrophs are able to grow in anaerobic environments, only aerobic methanotrophs have been isolated in pure culture and are genetically tractable. These

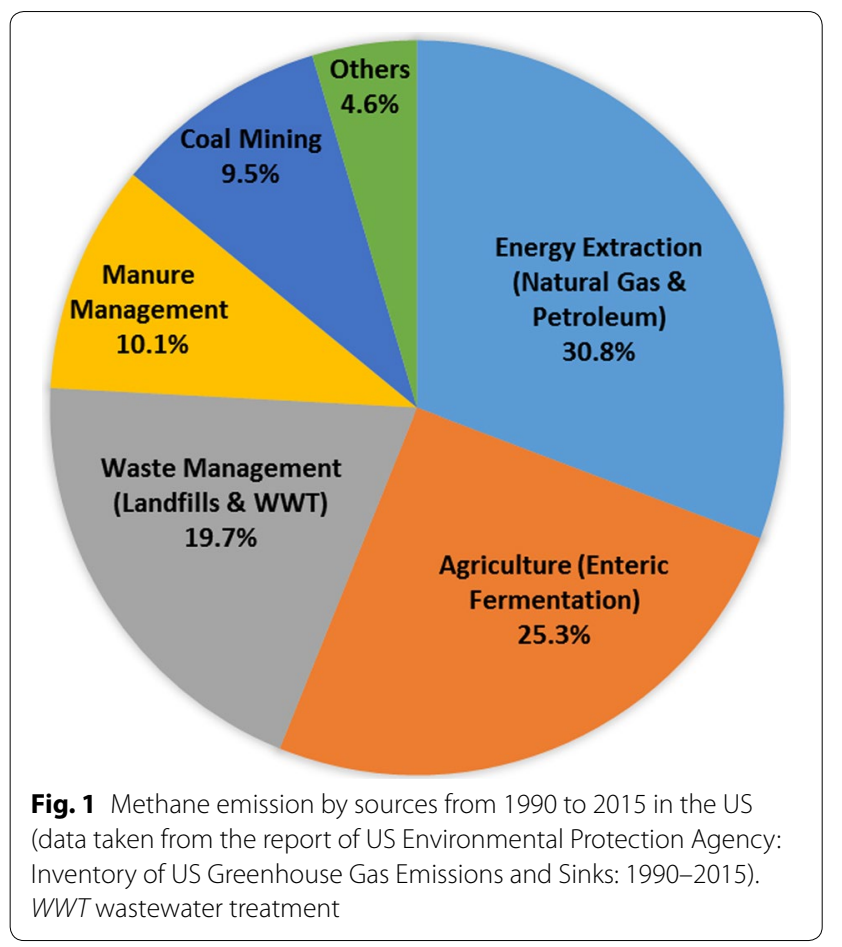

organisms can oxidize $\mathrm{CH}_{4}$ to methanol and beyond for both catabolism and anabolism and therefore have the ability to serve as a production platform for the conversion of $\mathrm{CH}_{4}$ into bio-based products [10-12].

Biofuels are an important component of a global effort to replace fossil fuels with renewable sources of energy due to enormous demand in terms of environmental issues, sustainable considerations, and greenhouse gas emissions, and methane-based biological gas to liquids (Bio-GTL) technologies could contribute to the various biofuel strategies under development [13, 14]. In 2013, a program announced by the Advanced Research Projects Agency-Energy (ARPA-E) of the US Department of Energy, named Reducing Emissions using Methanotrophic Organisms for Transportation Energy (REMOTE), was initiated to accelerate the development of economic processes for bioconversion of $\mathrm{CH}_{4}$ into liquid fuels [6]. One biocatalyst selected for this work was the methanotroph Methylomicrobium buryatense, which grows robustly at a range of $\mathrm{pH}$ and salinity levels [15]. $M$. buryatense is an aerobic gammaproteobacterium that oxidizes methane to methanol and then formaldehyde, which is subsequently incorporated into cellular biomass via the ribulose monophosphate cycle (Fig. 2). A set of genetic tools have been developed for M. buryatense [16, 17], and have been used to engineer this microorganism to produce lactic acid [18] as well as increase fatty acid levels during growth on $\mathrm{CH}_{4}[19,20]$.

Fatty acids and glycerolipids such as phosphatidyl ethanolamine (PE) and phosphatidyl glycerol (PG) are included among the list of cellular components produced during growth on $\mathrm{CH}_{4}$. These are incorporated into membranes, which can be upgraded to diesel blend stocks for biofuel through a catalytic process known as hydrodeoxygenation [6]. A lab-scale demonstration of an integrated biorefinery process was successfully developed recently, in which process membrane lipids produced by $M$. buryatense were converted into green diesel [21]. Gilman et al. investigated effects of $\mathrm{CH}_{4}$ and $\mathrm{O}_{2}$ limitation on $M$. buryatense growth and lipid production in continuous cultures, and discovered that oxygen-limited condition provided the highest dry cell weight (DCW) of $0.79 \mathrm{~g} / \mathrm{L}$ and lipid content of $10.7 \%(\mathrm{w} / \mathrm{w})$ [22]. Although the production performance of that research in terms of cell density and lipid productivity was low compared with oleaginous yeasts growing on sugars or microalgae growing photosynthetically with $\mathrm{CO}_{2}$, the results provided the basis for improvement in the work described here.

In order to provide more insights into using $M$. buryatense in an industrial setting, this study summarizes our efforts to achieve high lipid titer and productivity in high cell density cultures. Additionally, a mutant strain $(M$. buryatense AP18) in which the carbon sink of glycogen 


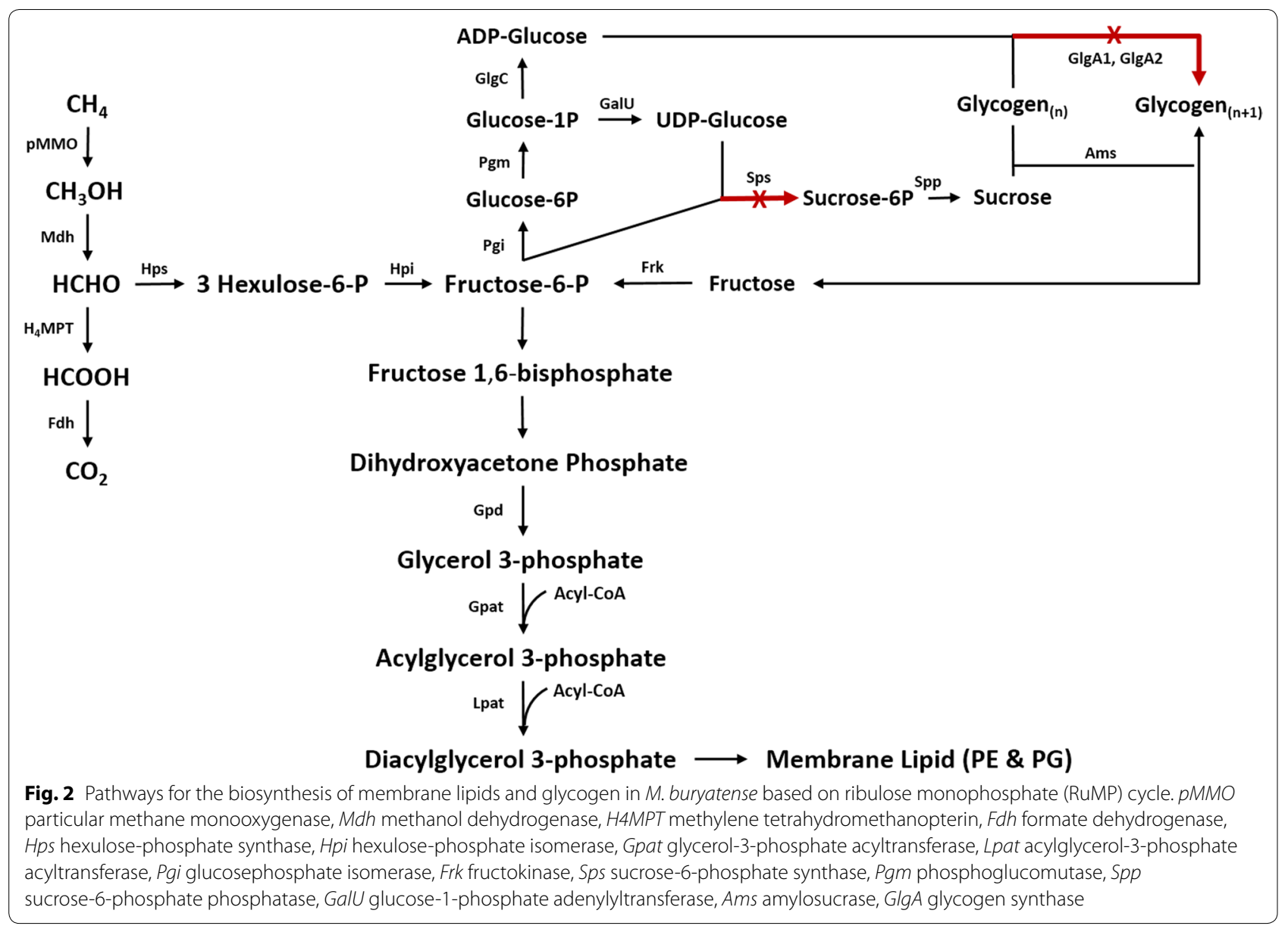

was eliminated was constructed and tested under the same conditions. The cell growth and lipid production from both strains were studied and compared in order to elucidate the influence of culture conditions on lipid production, gas uptake/evolution rates, and glycogen accumulation in batch cultures. Finally, the fatty acid compositions of lipids produced by $5 \mathrm{~GB} 1$ and AP18 were analyzed and characterized for diesel fuel production.

\section{Methods}

\section{Strain, media, and chemicals}

The frozen stocks of $M$. buryatense 5GB1 and its mutants were preserved under $-80{ }^{\circ} \mathrm{C}$ with DMSO as described previously [15]. For seed cultures, $M$. buryatense 5GB1 and AP18 were grown at $\mathrm{pH} 9.0 \pm 0.2$ using a defined NMS2 medium [17] containing the following, per liter of distilled water: $\mathrm{KNO}_{3} 2 \mathrm{~g}, \mathrm{MgSO}_{4} \cdot 7 \mathrm{H}_{2} \mathrm{O} 1 \mathrm{~g}, \mathrm{CaCl}_{2} \cdot 6 \mathrm{H}_{2} \mathrm{O}$ $0.02 \mathrm{~g}, \mathrm{NaCl} 7.5 \mathrm{~g}$, phosphate solution $\left(\mathrm{KH}_{2} \mathrm{PO}_{4} 5.44 \mathrm{~g} / \mathrm{L}\right.$ and $\left.\mathrm{Na}_{2} \mathrm{HPO}_{4} 10.73 \mathrm{~g} / \mathrm{L}\right) 20 \mathrm{~mL}$, carbonate solution (1 M $\mathrm{NaHCO}_{3} 700 \mathrm{~mL}$ and $\left.1 \mathrm{M} \mathrm{Na}_{2} \mathrm{CO}_{3} 300 \mathrm{~mL}\right) 50 \mathrm{~mL}$, and trace element solution $1 \mathrm{~mL}$ [23]. $\mathrm{CH}_{4}$ of $99.97 \%$ purity (United States Welding Inc, Denver, USA) was used as the sole carbon source for all cultures. Due to safety considerations, a gas mixture with $20 \% \mathrm{CH}_{4}$ and $80 \%$ air (v/v) was used for this study to avoid the flammable zone [24]. A continuous gas delivery system was used to supply the gas mixture for all $\mathrm{CH}_{4}$ cultures. Unless otherwise stated, all chemicals were purchased from Sigma-Aldrich Co. LLC (St. Louis, MO, US).

\section{Plasmid and strain construction}

Strains and plasmids used in this study are listed in Table 1 . The plasmid pAB2 for creating an unmarked deletion of the sucrose-phosphate synthase gene in $M$. buryatense (sps, MaGE [25] locus tag MBURv2_130613) was constructed using Gibson Assembly [26]. The primers used are listed in Table 2, and the vector backbone of a kanamycin-resistant version of pCM433 was amplified from the plasmid pAWP45 [17]. The PCR template for amplification of the sps flanking regions was genomic DNA extracted from $M$. buryatense 5GB1 using the DNeasy blood and tissue kit number 69504 (Qiagen, Hilden, Germany). To construct the 
Table 1 Strains and plasmids used in this study

\begin{tabular}{|c|c|c|}
\hline Strain/plasmid & Description & References \\
\hline \multicolumn{3}{|l|}{ Strains } \\
\hline E. coliTOP10 & $\begin{array}{l}\text { F-mcrA } \triangle \text { (mrr-hsdRMS-mcrBC) } \Phi 80 \text { lacZDM15 } \triangle \text { lacX74 recA1 araD139 } \triangle \text { (ara leu) } 7697 \text { galU galk } \\
\text { rpsL (StrR) endA1 nupG }\end{array}$ & Invitrogen \\
\hline E. colis17-1 $\lambda$ pir & Donor strain. $\mathrm{Tp}^{\mathrm{R}} \mathrm{Sm}^{\mathrm{R}}$ recA, thi, pro, hsd $\left(\mathrm{R}^{-} \mathrm{M}^{+}\right) \mathrm{RP4}$ : 2-Tc:Mu: Km Tn7 $\lambda$ pir & [27] \\
\hline M. buryatense $5 \mathrm{~GB} 1$ & Moderately haloalkaliphilic methanotroph & [17] \\
\hline M. buryatense $5 G B 1 \triangle g \lg A 1 \triangle g \lg A 2$ & M. buryatense $5 G B 1 \triangle g \lg A 1 \triangle g \lg A 2$ & [17] \\
\hline AP18 & M. buryatense $5 \mathrm{~GB} 1 \mathrm{C}[17] \triangle g \lg A 1 \Delta g \lg A 2 \Delta s p s$ & This study \\
\hline \multicolumn{3}{|l|}{ Plasmids } \\
\hline pAWP93 & pCM433kanT containing flanks to knock out repA-repB locus of native plasmid. & [17] \\
\hline $\mathrm{pAB2}$ & Kanamycin-resistant variant of pCM433 containing flanks to knock out sps & This study \\
\hline
\end{tabular}

Table 2 Primers used in this study

\begin{tabular}{|c|c|c|}
\hline Primer name & Sequence $\left(5^{\prime}-3^{\prime}\right)$ & Description \\
\hline AP186_pCM433kanT_fwd1 & ATGTGCAGGTTGTCGGTGTC & \multirow{2}{*}{$\begin{array}{l}\text { For amplifying the backbone of } \\
\text { the KanR version of the sucrose } \\
\text { counterselection plasmid } \\
\text { pCM433 [17] }\end{array}$} \\
\hline AP187_pCM433kanT_rev1 & TGGTAACTGTCAGACCAAGTTTACTC & \\
\hline AP110_spsKO_UP_Fwd & ATTGGTACCATGGATGCATATGCTGCAGCTACGCTGCTCTAAATACCTTG & \multirow{4}{*}{$\begin{array}{l}\text { For amplifying flanks to knock } \\
\text { out sps (MaGE locus tag } \\
\text { MBURv2_130613) using plasmid } \\
\text { pAB2 }\end{array}$} \\
\hline AP111_spsKO_UP_Rev & ICTGCTCTCAGTCACGATCGTACTCACTTCAGCTG & \\
\hline AP112_spsKO_DWN_Fwd & GAAGTGAGTACGATCGTGACTGAGAGCAGAATTATGACTG & \\
\hline AP113_spsKO_DWN_Rev & AGTGAGCTCACCGGTTAACACGCGTACGTACCTTCGGCCAAATACAACGA & \\
\hline
\end{tabular}

Homology regions used for Gibson assembly are underlined

triple knock out strain AP18, pAB2 was introduced into the strain 5GB1 $\triangle g l g A 1 \triangle g l g A 2$ via conjugation and sucrose counterselection was performed as previously described [17]. In brief, $M$. buryatense 5GB1 $\triangle g l g A 1 \triangle \operatorname{glg} A 2$ was spread onto an NMS2 mating plate and grown overnight. An equal volume of $E$. coli S17-1 $\lambda$ pir donor cells containing pAB2 was then added to the plate for conjugation, and the resulting mixture was incubated at $30{ }^{\circ} \mathrm{C}$ for 2 days. The mixture of cells was then spread onto NMS2 plates containing kanamycin $(50 \mu \mathrm{g} / \mathrm{mL})$ to select for transconjugants, which were subsequently purified from the donor via passaging on NMS2 plates containing rifamycin $(50 \mu \mathrm{g} / \mathrm{mL})$. For counterselection, double crossovers were selected by plating kanamycin-resistant transconjugants (single crossovers) onto NMS2 containing 2.5\% sucrose and rifamycin. Colonies were then checked for kanamycin sensitivity and genotyped via PCR, using either colonies as the PCR template or DNA extracted with DNeasy blood and tissue kit (\#69504 Qiagen, Hilden, Germany). Subsequently, this strain was cured of the native $80-\mathrm{kb}$ plasmid using vector pAWP93, in order to enable this strain to accept small plasmids for heterologous expression in future studies as previously described [17].

\section{Culture conditions}

A loop of colonies taken from an agar plate was used to inoculate seed cultures in defined NMS2 medium in a 300-mL spinner bottle (Bellco Glass, Inc., Vineland, NJ) at $30^{\circ} \mathrm{C}$ and $250-280 \mathrm{rpm}$. The spinner bottles resided in a water bath to maintain the culture temperature, and a five-position magnetic stir plate was located beneath the water bath for agitation. The seed culture was agitated for 24-36 h until the optical density $\left(\mathrm{OD}_{600}\right)$ reached $8 \pm 0.5$. Production cultures with $10 \%$ inocula were grown with the same defined NMS2 medium as the seed culture except using $4 \times \mathrm{KNO}_{3}, 2 \times \mathrm{mL}$ phosphate solution and $4 \times$ of trace solution.

A continuous gas delivery and monitoring system was utilized to supply the gas mixture for all batch cultures as described previously [22]. Production cultures were carried out using a Biostat Q-Plus fermentation system (Sartorius, Goettingen, Germany), which was set to control $\mathrm{pH}$ at $9.0 \pm 0.2$ with $2 \mathrm{M} \mathrm{NaOH}$. Dissolved $\mathrm{O}_{2}$ was monitored with an Ingold polarographic probe and the agitation speed was manually controlled with a maximum rate of $1000 \mathrm{rpm}$. The flow rate of the gas mixture $\left(\mathrm{CH}_{4}\right.$ and air $)$ was controlled by a digital on-line mass flow controller (Vögtlin Instruments, Aesch, Switzerland) at $300-900 \mathrm{~mL} / \mathrm{min}$ depending on the experiment to 
give a $\mathrm{CH}_{4} / \mathrm{O}_{2}$ ratio of 5:4 to meet safety considerations. To prevent excessive foam formation, a $1 \%$ sterile antifoam solution (PPG-PEG-PPG, CAS Number 9003-116, Sigma-Aldrich. Co, USA) was added manually during production cultures. The $\mathrm{CH}_{4}, \mathrm{O}_{2}$, and $\mathrm{CO}_{2}$ in the off-gas stream from bioreactors were monitored and analyzed by gas sensors (BlueSens, Recklinghausen, Germany) in order to calculate gas uptake/evolution rates $(\mathrm{mmol} / \mathrm{L} / \mathrm{h})$. All presented results in this study were averaged from experiments carried out in duplicate.

\section{Analyses}

Cell growth was estimated by measuring OD at $600 \mathrm{~nm}$ [28]. For cell mass analyses, $10 \mathrm{~mL}$ of culture broth was transferred to a pre-weighed centrifuge tube and centrifuged at $5000 \mathrm{rpm}$ for $30 \mathrm{~min}$. After rinsing once with deionized water, the pellet was dried for $24-48 \mathrm{~h}$ in a lyophilizer for DCW measurement and lipid analysis [29]. A modified Megazyme procedure (AA/AMG 11/01, AOAC Method 996.11, AACC Method 76.13, ICC Standard Method No. 168) was used to determine the glycogen content of lyophilized bacterial biomass. In summary, 10 to $25 \mathrm{mg}$ of lyophilized cell mass was weighed out into $15-\mathrm{mL}$ plastic centrifuge tubes. To each sample was added $50 \mu \mathrm{L}$ 190-proof ethanol and $500 \mu \mathrm{L}$ DMSO, and subsequently the samples were placed in a boiling water bath for $5 \mathrm{~min}$. After boiling, $725 \mu \mathrm{L}$ of MOPS buffer and $25 \mu \mathrm{L}$ of thermostable $\alpha$-amylase were added to each sample and vortexed. Samples were then incubated in a boiling water bath for $12 \mathrm{~min}$, vortexing every $2 \mathrm{~min}$. After $12 \mathrm{~min}$, samples were removed from the water bath and $1 \mathrm{~mL}$ of sodium acetate buffer and $25 \mu \mathrm{L}$ of amyloglucosidase were added and samples were vortexed. Samples were then placed into a $50{ }^{\circ} \mathrm{C}$ water bath. After $30 \mathrm{~min}$, samples were removed from the water bath and centrifuged at $3000 \mathrm{rpm}$ for $5 \mathrm{~min}$. An aliquot of each sample was filtered through a $0.2-\mu \mathrm{m}$ nylon filter and run on an HPLC equipped with a Biorad Aminex HPX-87H column $\left(55-65{ }^{\circ} \mathrm{C}\right)$ and an RID detector. A $0.01 \mathrm{~N}$ sulfuric acid mobile phase at $0.6 \mathrm{~mL} / \mathrm{min}$ was used.

\section{Results and discussion}

Effects of agitation rates on lipid production by $M$. buryatense 5GB1

Due to the extremely low solubility of $\mathrm{CH}_{4}$ and $\mathrm{O}_{2}$, which are both required for cell growth and lipid production, the cultivation of methanotrophs can be severely limited by the gas transfer efficiency [30,31]. Increasing the agitation rate is the simplest way to improve gas transfer efficiency in a continuous stirred tank bioreactor (CSTR), in which a sparger at the bottom of the CSTR delivers gases into the liquid phase [32]. The agitation rate of the stirring blades inside the CSTR is controlled to break down bubbles into smaller sizes in order to increase the gas-liquid interfacial area and to keep them from offgassing quickly, resulting in a better gas transfer efficiency. Two different agitation rates (500 and $1000 \mathrm{rpm}$ ) with a gas flow rate of $300 \mathrm{ccm}$ were first tested to gain a basic understanding of the effect of agitation rates on cell growth and lipid production in batch cultures of 5GB1 with continuous feeding of $\mathrm{CH}_{4}$ and $\mathrm{O}_{2}$. As shown in Table 3, improved cell density (DCW) was obtained under higher agitation rate, which corresponds to a $30 \%$ enhancement in cell density compared with previous highest reported data $(10.2 \mathrm{~g} / \mathrm{L})$ from cultures of 5GB1 [21]. Although a higher lipid content of $9.6 \%$ was observed with lower agitation rate, a $30-60 \%$ increase in lipid productivity was achieved in cultures with $1000 \mathrm{rpm}$, which corresponds to 32.3 and $17.9 \mathrm{mg} / \mathrm{L} / \mathrm{h}$ at 24 and $48 \mathrm{~h}$, respectively. Interestingly, we also found that $M$. buryatense 5GB1 accumulated glycogen under both conditions, but the $1000 \mathrm{rpm}$ agitation rate resulted in a higher glycogen content of $18.7 \%$ (Table 3 ), which is much higher than previously reported in low cell density batch cultures of $M$. buryatense (2.7\%) [22]. The high glycogen content obtained from cultures with higher agitation rate indicates a change in the metabolic balance of the cell, such as increased activity of glycogen synthase under this growth condition. This may explain the drop in lipid content from 7.9 to $6.1 \%$ as more carbon is devoted to glycogen production.

Table 3 Lipid and glycogen (Gly) production by M. buryatense 5GB1 with the gas flow rate of $300 \mathrm{ccm}$ under two different agitation rates

\begin{tabular}{|c|c|c|c|c|c|c|c|c|}
\hline \multirow[t]{2}{*}{ Time } & \multicolumn{4}{|l|}{$500 \mathrm{rpm}$} & \multicolumn{4}{|l|}{$1000 \mathrm{rpm}$} \\
\hline & DCW, g/L & Lipid, \% & $\mathrm{Pr}_{\mathrm{L}}, \mathrm{mg} / \mathrm{L} / \mathrm{h}$ & Gly, \% & $\mathrm{DCW}, \mathrm{g} / \mathrm{L}$ & Lipid, \% & $\mathrm{Pr}_{\mathrm{L}}, \mathrm{mg} / \mathrm{L} / \mathrm{h}$ & Gly, \% \\
\hline 24 & $5.0 \pm 0.3$ & $9.8 \pm 0.4$ & $20.4 \pm 1.2$ & $2.2 \pm 0.5$ & $9.8 \pm 1.2$ & $7.9 \pm 0.5$ & $32.3 \pm 1.9$ & $12.3 \pm 1.5$ \\
\hline 48 & $6.8 \pm 0.5$ & $9.6 \pm 0.2$ & $13.6 \pm 0.4$ & $1.8 \pm 0.1$ & $14.1 \pm 0.9$ & $6.1 \pm 0.3$ & $17.9 \pm 0.8$ & $18.7 \pm 1.4$ \\
\hline
\end{tabular}

$\mathrm{Pr}_{L}$ lipid productivity 
Enhanced lipid production by $M$. buryatense 5GB1 in high cell density cultivation

Because lipids produced by $M$. buryatense are in the form of intracellular membranes, the productivity of lipids is a function of both the cellular lipid titer and the cell density in culture, which is in agreement with the aforementioned findings (Table 3). Therefore, high cell density cultivation could be an important strategy to improve methanotrophic cultivation for the liquid fuel production. Both high gas flow rate $(900 \mathrm{ccm})$ and high agitation rate (1000 $\mathrm{rpm})$ were employed to achieve high cell density cultures for the lipid production. As shown in Figs. 3 and 4, an OD of 55 with a maximum specific growth rate of $0.22 \mathrm{~h}^{-1}$ was observed during the batch cultures, in which the maximum $\mathrm{O}_{2}$ and $\mathrm{CH}_{4}$ utilization rates measured were 80.6 and $51.1 \mathrm{mmol} /$ $\mathrm{L} / \mathrm{h}$, respectively. After $24 \mathrm{~h}$, the growth rate began to slow down, presumably due to the exhaustion of nutrients in the medium, and the cultures exhibited lower

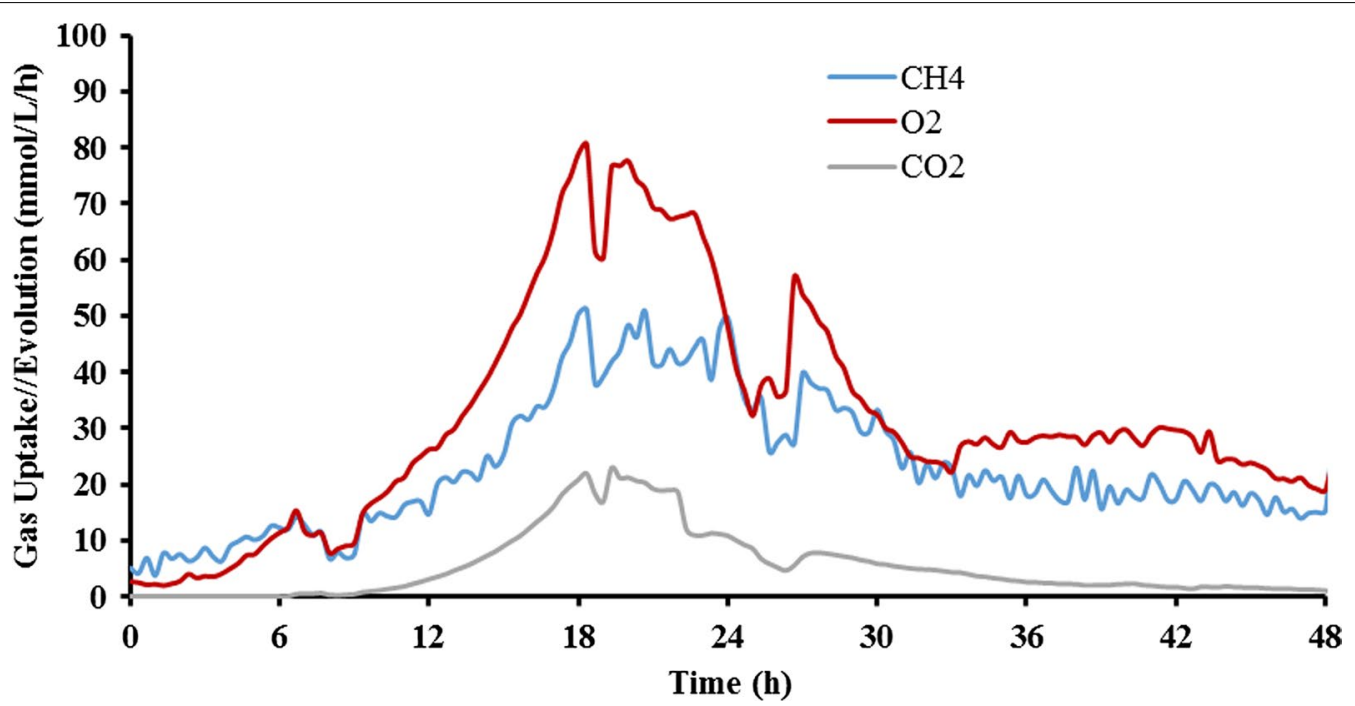

Fig. 3 Gas uptake $\left(\mathrm{CH}_{4}\right.$ and $\left.\mathrm{O}_{2}\right)$ rate and $\mathrm{CO}_{2}$ evolution rate in the cultivation of $M$. buryatense $5 \mathrm{~GB} 1$ for lipid production

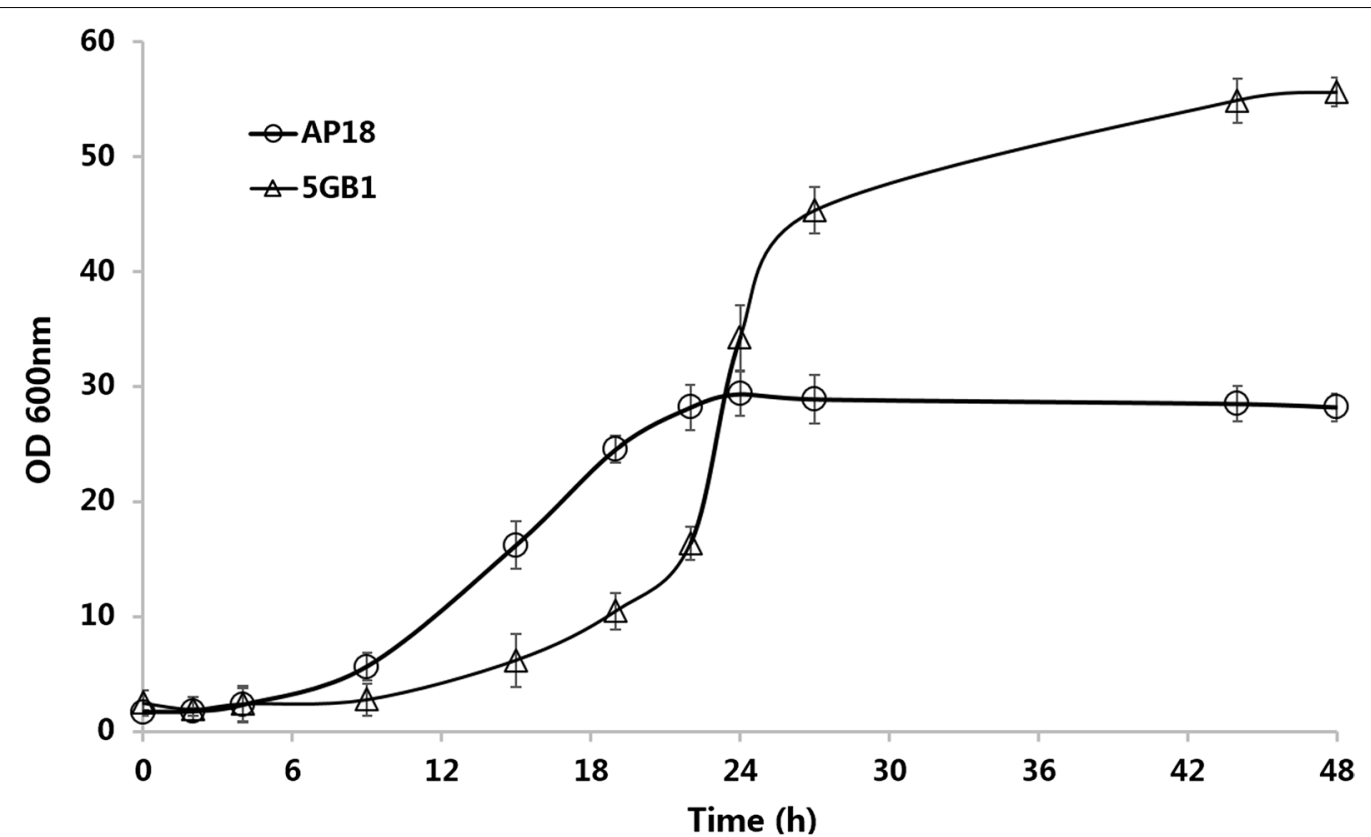

Fig. 4 Comparison of growth profile of M. buryatense 5GB1 and AP18 in batch cultures 
gas utilization rates along with increasing dissolved $\mathrm{O}_{2}$ indicating the end of the cultivation.

The highest DCW of $21.4 \mathrm{~g} / \mathrm{L}$ along with a maximum lipid productivity of $36.1 \mathrm{mg} / \mathrm{L} / \mathrm{h}$ was accomplished in high cell density cultures of $M$. buryatense 5GB1 (Table 4), which presents a 4-fold cell density improvement and $60 \%$ increase in lipid productivity, compared with that observed in the culture agitated at $500 \mathrm{rpm}$. Although enhanced lipid production performance was obtained, lipid content surprisingly decreased from 6.5 to $4.9 \%$ during the cultivation, which is substantially lower than values previously recorded from low cell density cultures [22]. Since the goal of this study is to generate high biomass titer with high lipid content to serve as feedstock for extraction and upgrading to diesel fuel, this approach for high cell density cultures was a limited success. The observed decrease in lipid content may be the result of nutrient depletion in the medium, which would result in decreased expression of membrane-bound particulate methane monooxygenase [33], combined with the accumulation of intracellular glycogen also observed in previous experiments.

As shown in Table 4, the glycogen content in $M$. buryatense 5GB1 significantly increased to $35.9 \%$ when grown under high cell density culture conditions. These growth conditions cause $M$. buryatense 5GB1 to shift carbon flux to glycogen accumulation at the expense of cell division and membrane synthesis. It has been reported that up to $35 \%$ glycogen content can be obtained in cultures of Methylomicrobium species using methanol $[22,34]$. However, this is the first time that such high glycogen content has been reported for cultures of $M$. buryatense grown on $\mathrm{CH}_{4}$ as the sole carbon source. Therefore, although lipid production was improved in high cell density cultures, the great amount of glycogen produced is a significant competing carbon sink that limits lipid biosynthesis [22].

Table 4 Cell growth, lipid production, and glycogen accumulation in the cultivation of $M$. buryatense 5GB1 and AP18 with the flow rate of $900 \mathrm{ccm}$ and agitation of $1000 \mathrm{rpm}$

\begin{tabular}{lllll}
\hline Strain & 5GB1 & \multicolumn{3}{c}{ AP18 } \\
\hline $\begin{array}{l}\text { Culture } \\
\text { time, } h\end{array}$ & 24 & 48 & 24 & 48 \\
DCW, g/L & $13.3 \pm 1.0$ & $21.4 \pm 1.6$ & $11.7 \pm 0.4$ & $15.3 \pm 1.1$ \\
Lipid, mg/L & $864.3 \pm 37.2$ & $1056.2 \pm 41.3$ & $1090.2 \pm 30.5$ & $1453.5 \pm 54.5$ \\
Lipid, \% & $6.5 \pm 0.4$ & $4.9 \pm 0.6$ & $9.3 \pm 0.3$ & $9.5 \pm 0.4$ \\
PrL, mg/L/h & $36.1 \pm 2.2$ & $22.0 \pm 1.3$ & $45.4 \pm 1.7$ & $30.3 \pm 0.9$ \\
Gly, \% & $27.6 \pm 3.2$ & $35.9 \pm 2.6$ & 0.0 & 0.0 \\
\hline
\end{tabular}

It has been reported that the carbon flux can be significantly enhanced in various microorganisms by limiting synthesis pathways of byproducts [35-37]. The enhancement of lipid accumulation has been demonstrated by blocking the starch synthesis in Chlamydomonas reinhardtii under nitrogen limitation condition [38]. Han et al. have recently increased the lipid productivities of Tetraselmis sp. up to $30 \%$ via regulating the carbon flux from starch synthesis to lipid production [39]. In an attempt to limit production of glycogen, a 5GB1 $\triangle g l g A 1$ $\triangle g l g A 2$ mutant, which did not produce any glycogen under previously tested low cell density batch conditions [17] was tested and grown under the high cell density culture conditions used in the initial experiments of this study (agitation of $1000 \mathrm{rpm}$ and a flow rate of $300 \mathrm{ccm}$ ). However, under this setup, the double knockout mutant is still able to accumulate $6.4 \%$ glycogen in a 48 -h batch cultivation (data not shown). To address this finding, a new strain was constructed by knocking out the gene encoding for sucrose-6-phosphate synthase (sps) in addition to the two glycogen synthase genes, $g \lg A 1$ and $g \lg A 2$. This latter gene was targeted because members of this genus of methanotrophs can also synthesize glycogen via sucrose degradation as shown in Fig. $2[40,41]$. This triple knockout mutant strain was also cured of 5GB1's native plasmid to enable plasmid-based heterologous expression [17] in other studies [20], resulting in the strain AP18 (5GB1C $\triangle g l g A 1 \triangle g l g A 2 \Delta s p s)$.

\section{Effects of the limitation of glycogen biosynthesis on cell growth and lipid production}

For the first time, the effect of limiting glycogen biosynthesis on cell growth and lipid production in high cell density cultures was investigated. The performance of 5GB1 and AP18 was compared in terms of cell density, lipid production, and glycogen accumulation under high cell density culture conditions. As shown in Fig. 4, AP18 reached stationary phase at a lower optical density and had a lower maximum growth rate compared with 5GB1 (the decrease in OD of AP18 was observed after 48 h, data not shown in Fig. 4). However, the glycogen content in AP18 biomass was below detection limits and a consistently high lipid content above $9 \%$ was observed throughout cultivation (Table 4), resulting in a $90 \%$ increase relative to $5 \mathrm{~GB} 1$. Finally, a maximum lipid productivity of $45.4 \mathrm{mg} / \mathrm{L} / \mathrm{h}$ was also achieved by AP18, which presents a $20 \%$ improvement over $5 \mathrm{~GB} 1$ and a 3 -fold improvement in lipid production, compared with previous reported data $(13.3 \mathrm{mg} / \mathrm{L} / \mathrm{h})$ from cultures of 5GB1 [21].

Although no glycogen was accumulated in AP18, the final DCW of $15.3 \mathrm{~g} / \mathrm{L}$ from AP18 was surprisingly lower than that seen with 5GB1. After analyzing the gas 
uptake and evolution in cultures of AP18 (Fig. 5), both specific $\mathrm{CH}_{4}$ and $\mathrm{O}_{2}$ uptake rates were found to be $45 \%$ higher than that in cultures of 5GB1 (Table 5). Interestingly, the specific $\mathrm{CO}_{2}$ evolution rate was increased by more than $100 \%$ in cultures of AP18 (comparing results in Fig. 5 with those in Fig. 3), which could be due to a need for more reducing power in this mutant. It has been reported that culture conditions can significantly influence the metabolic networks of Methylomicrobium species in terms of metabolic networks and NADH production $[16,17]$, but further investigation will be needed to understand the phenomenon observed in this study. Overall, even though the cell density of AP18 was lower than that of 5GB1 in high cell density culture conditions, the primary metrics for improved biomass production are lipid productivity and content and from this point of view, AP18 clearly exceeded 5GB1 in both of these categories.

Fatty acid composition of membrane lipids produced by $M$. buryatense using $\mathrm{CH}_{4}$ as the sole carbon source

As shown in Table 6 , lipids produced by $M$. buryatense 5GB1 in high cell density cultures were composed mainly of myristic acid (C14:0), palmitic acid (C16:0), and palmitoleic acid (C16:1), which is in good agreement with previous reports $[21,23]$. The composition of fatty acids showed only minor changes between 5GB1 and AP18. It has been reported that the fatty acid composition can affect the cetane number $(\mathrm{CN})$, which is one of the most significant properties to specify the quality of biofuels for use in a diesel engine [42]. According to the equation developed by Bamgboye et al. [43], CN values of lipids
Table 5 Comparison of cell growth and lipid production by $M$. buryatense under high cell density culture conditions

\begin{tabular}{lcc}
\hline Strain & 5GB1 & AP18 \\
\hline DCW, g/L & 21.4 & 15.3 \\
Maximum $\mathrm{O}_{2}$ uptake rate, $\mathrm{mmol} / \mathrm{L} / \mathrm{h}$ & 80.6 & 87.8 \\
Maximum $\mathrm{CH}_{4}$ uptake rate, $\mathrm{mmol} / \mathrm{L} / \mathrm{h}$ & 51.1 & 54.4 \\
Maximum $\mathrm{CO}_{2}$ evolution $\mathrm{rate}, \mathrm{mmol} / \mathrm{L} / \mathrm{h}$ & 22.9 & 35.9 \\
Specific $\mathrm{O}_{2}$ uptake rate ${ }^{a}, \mathrm{mmol} / \mathrm{gDCW} / \mathrm{h}$ & 3.8 & 5.7 \\
Specific $\mathrm{CH}_{4}$ uptake rate ${ }^{a}, \mathrm{mmol} / \mathrm{gDCW} / \mathrm{h}$ & 2.4 & 3.5 \\
Specific $\mathrm{CO}_{2}$ evolution rate ${ }^{\mathrm{a}}, \mathrm{mmol} / \mathrm{gDCW} / \mathrm{h}$ & 1.1 & 2.3 \\
\hline
\end{tabular}

a Calculated by using the maximum gas uptake/evolution rates and the highest DCW from cultures of different strains

produced by different microbes using various carbon substrates are estimated and listed in Table 6. Compared to other strains, $M$. buryatense showed a relatively high $\mathrm{CN}$ value of 75 , which is $50 \%$ higher than the minimal $\mathrm{CN}$ value of biofuel standards set by EU and the US [44]. Our findings suggest that $\mathrm{CH}_{4}$-derived lipids from $M$. buryatense can be a very promising alternative source for the liquid fuel production.

\section{Conclusions}

In this study, high cell density cultures of different $M$. buryatense strains grown with $\mathrm{CH}_{4}$ as the sole carbon and energy source were used for the production of the microbial lipid, a potential feedstock for liquid transportation fuels. The highest observed DCW of $21.4 \mathrm{~g} / \mathrm{L}$ was obtained in batch cultures of $5 \mathrm{~GB} 1$ with high agitation and flow rate, whereas this high cell

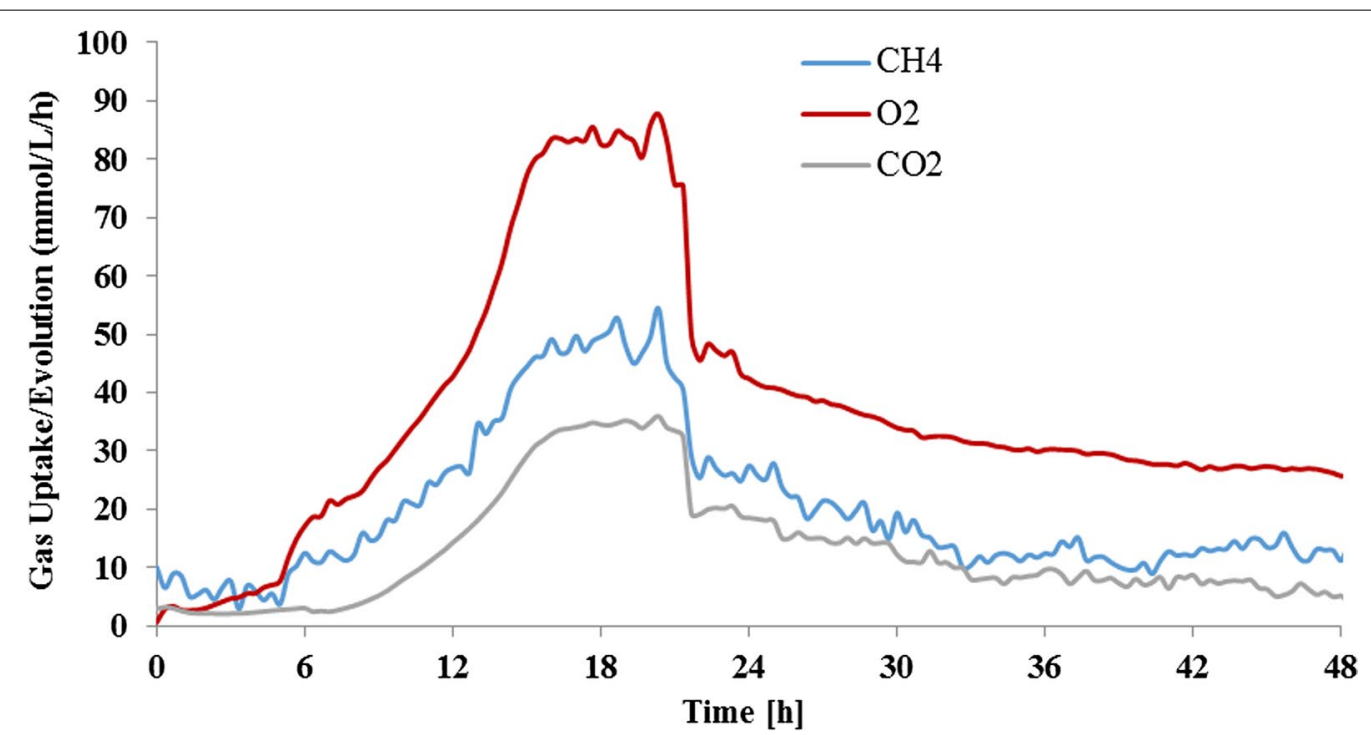

Fig. 5 Gas uptake $\left(\mathrm{CH}_{4}\right.$ and $\left.\mathrm{O}_{2}\right)$ rate and $\mathrm{CO}_{2}$ evolution rate in the cultivation of $M$. buryatense AP1 8 for lipid production 
Table 6 Comparison of fatty acid compositions from different microbes and substrates

\begin{tabular}{|c|c|c|c|c|c|c|c|c|c|c|}
\hline Microbe & Substrate & C14:0 & C16:0 & C16:1 & C18:0 & C18:1 & C18:2 & C18:3 & $\mathrm{CN}$ & References \\
\hline M. buryatense 5GB1 & $\mathrm{CH}_{4}$ & $7.1 \pm 0.3$ & $16.9 \pm 0.5$ & $73.5 \pm 0.9$ & $\operatorname{tr}$ & $\operatorname{tr}$ & nd & nd & 75.1 & This work \\
\hline M. buryatense AP18 & $\mathrm{CH}_{4}$ & $4.9 \pm 0.2$ & $16.8 \pm 0.7$ & $75.5 \pm 0.6$ & $\operatorname{tr}$ & $\operatorname{tr}$ & nd & nd & 75.2 & This work \\
\hline C. vulgaris (microalga) & $\mathrm{CO}_{2}$ & nd & 24.0 & 2.1 & 1.3 & 24.8 & 47.8 & nd & 51.9 & {$[45]$} \\
\hline S. obtusiusculus (microalga) & $\mathrm{CO}_{2}$ & nd & 30.2 & 7.3 & nd & 45.7 & nd & 12.6 & 59.5 & {$[46]$} \\
\hline Synechocystis sp. (cyanobacterium) & $\mathrm{CO}_{2}$ & nd & 52.0 & 4.0 & nd & 4.0 & 14.0 & 25.0 & 55.2 & {$[47]$} \\
\hline R. toruloides (yeast) & Glucose & 1.3 & 25.1 & nd & 10.4 & 46.4 & 10.8 & 3.4 & 57.7 & [48] \\
\hline
\end{tabular}

nd not detected, $\operatorname{tr}$ less than $1 \%, C N$ the cetane number was calculated as described by Bamgboye and Hansen [43]

$\mathrm{CN}=61.1+0.088 \times 2+0.133 \times 3+0.152 \mathrm{X} 4-0.101 \times 5-0.039 \mathrm{X} 6-0.243 \mathrm{X} 7-0.395 \mathrm{X} 8$, where $\mathrm{X} 2$ to $\mathrm{X} 8$ indicate the weight percentages of methyl esters, as follows: C14:0, C16:0, C16:1, C18:0, C18:1, C18:2, C18:3, respectively

density was accompanied by high levels of glycogen and relatively low levels of lipid. One explanation for this could be that at high cell density, 5GB1 metabolism shifts to produce glycogen, and nutrient limitation may also result in down regulation of pMMO synthesis and concomitant reduction in intracellular membrane and membrane lipids [40]. To enhance the carbon flux from $\mathrm{CH}_{4}$ to lipids, a mutant (AP18) where glycogen production is abrogated was constructed and used in this research. AP18 provided both high DCW of $15.3 \mathrm{~g} / \mathrm{L}$ and high lipid productivity of $45.4 \mathrm{mg} / \mathrm{L} / \mathrm{h}$. A lipid content of up to $9.3 \%$ with undetectable levels of glycogen accumulation was also achieved by AP18, which may therefore serve as a base strain for additional attempts to increase lipid production. Overall, the highest DCW and lipid productivity obtained under high cell density culture conditions present a 2 -fold enhancement in cell density and 3-fold improvement in lipid production compared with previous reported data from cultures of $5 \mathrm{~GB} 1$ [21].

It should be noted that increased $\mathrm{CH}_{4} / \mathrm{O}_{2}$ uptake rate and $\mathrm{CO}_{2}$ evaluation rate from AP18 cultures suggest more carbon $\left(\mathrm{CH}_{4}\right)$ and energy are needed to produce lipids by AP18. The resulting low carbon conversion efficiency could be a problem for the economics of the process. As the CSTR approach to cultivation of methanotrophs is highly inefficient and other reactor systems such as bubble columns are better suited for gas-based fermentations [49], it will become important to review the physiological response of 5GB1 and AP18 under high cell density culture conditions to determine if glycogen accumulation will impact lipid production under more commercially relevant conditions. The results of this study expand our understanding on the characteristics of $M$. buryatense under different culture conditions, which provided an insight for the practice of biofixation of $\mathrm{CH}_{4}$ for the production of microbial lipid-based bioproducts.

\section{Abbreviations}

CHP: combined heat and power; C14:0: myristate; C16:0: palmitate; C16:1: palmitoleate; C18:0: stearate; C18:1: oleate; C18:2: inoleate; C18:3: linolenate; $\mathrm{CN}$ : cetane number; $\mathrm{CO}_{2}$ : carbon dioxide; DCW: dry cell weight; rpm: rotations per minute; GHG: greenhouse gas; $\mathrm{H}_{2} \mathrm{O}$ : water; $\mathrm{HPLC}$ : high-performance liquid chromatography; OD: optical density; $\mathrm{CH}_{4}$ : methane; $\mathrm{O}_{2}$ : oxygen; RuMP: ribulose monophosphate; $\mathrm{PMMO}$ : particular methane monooxygenase; $\mathrm{MDH}$ : methanol dehydrogenase; LDH: lactate dehydrogenase; $\mathrm{PDH}$ : pyruvate dehydrogenase; GPD: glycerol-3-phosphate dehydrogenase; GPAT: glycerol3-phosphate acyltransferase; LPAT: acylglycerol-3-phosphate transferase; PE: phosphatidylethanolamine; PG: phosphatidylglycerol; NADH: nicotinamide adenine dinucleotide (reduced form).

\section{Authors' contributions}

QF designed and performed experiments and wrote this manuscript. PP advised on the design of the experiments and revised the manuscript. AWP performed experiments. HS prepared the culture medium and seed cultures. ND advised on the design of the cultivation. All authors read and approved the final manuscript.

\section{Author details}

${ }^{1}$ School of Chemical Engineering and Technology, Xi'an Jiaotong University, Xi'an, China. ${ }^{2}$ National Bioenergy Center, National Renewable Energy Laboratory, Golden, CO, USA. ${ }^{3}$ Department of Chemical Engineering, University of Washington, Seattle, WA, USA.

\section{Acknowledgements}

This work was supported by a Grant from the Advanced Research Projects Agency-Energy (ARPA-E) of US Department of Energy (0670-5169) and the Key Research and Development Program of Shaanxi Province, China (2017GY-146). The authors would like to thank Kelsey Ramirez, Stefanie Van Wychen, and Alan Bohn for their supporting roles in this work.

\section{Competing interests}

The authors declare that they have no competing interests.

\section{Availability of supporting data}

Not applicable.

\section{Consent for publication}

Not applicable.

Ethical approval and consent to participate

Not applicable.

Funding

This work was supported by a Grant from the Advanced Research Projects Agency-Energy (ARPA-E) of US Department of Energy (0670-5169).

\section{Publisher's Note}

Springer Nature remains neutral with regard to jurisdictional claims in published maps and institutional affiliations. 
Received: 22 July 2017 Accepted: 23 April 2018

Published online: 04 May 2018

\section{References}

1. Bousquet P, Ciais P, Miller J, Dlugokencky E, Hauglustaine D, Prigent C, et al. Contribution of anthropogenic and natural sources to atmospheric methane variability. Nature. 2006:443(7110):439-43.

2. EPA. Inventory of US Greenhouse Gas Emissions and Sinks: 1990-2015. US Environmental Protection Agency: US Environmental Protection Agency 2017

3. Prieto CVG, Ramos FD, Estrada V, Villar MA, Diaz MS. Optimization of an integrated algae-based biorefinery for the production of biodiesel, astaxanthin and PHB. Energy. 2017;139:1159-72.

4. Howarth RW. A bridge to nowhere: methane emissions and the greenhouse gas footprint of natural gas. Energy Sci Eng. 2014;2(2):47-60.

5. Elvidge CD, Bazilian MD, Zhizhin M, Ghosh T, Baugh K, Hsu FC. The potential role of natural gas flaring in meeting greenhouse gas mitigation targets. Energy Strategy Rev. 2018;20:156-62.

6. Fei Q, Guarnieri MT, Tao L, Laurens LML, Dowe N, Pienkos PT. Bioconversion of natural gas to liquid fuel: opportunities and challenges. Biotechnol Adv. 2014;32(3):596-614

7. Stanley A, Stanley D, Dadu D, Abah A. Appraising the combustion of biogas for sustainable rural energy needs. Afr J Environ Sci Technol. 2013;7(6):350-7.

8. Söhngen N. Uber bakterien, welche methan ab kohlenstoffnahrung and energiequelle gebrauchen. Parasitenkd Infectionskr Abt. 1906;15:513-7.

9. Whittenbury R, Phillips K, Wilkinson J. Enrichment, isolation and some properties of methane-utilizing bacteria. J Gen Microbiol. 1970;61(2):205-18.

10. Strong PJ, Laycock B, Mahamud SNS, Jensen PD, Lant PA, Tyson G, et al. The opportunity for high-performance biomaterials from methane. Microorganisms. 2016;4(1):11.

11. Clomburg JM, Crumbley AM, Gonzalez R. Industrial biomanufacturing: the future of chemical production. Science. 2017;355(38):1-10.

12. Cantera S, Lebrero R, Rodríguez S, García-Encina PA, Muñoz R. Ectoine biomilking in methanotrophs: A step further towards methane-based biorefineries into high added-value products. Chem Eng J. 2017;328(Supplement C):44-8. https://doi.org/10.1016/i.cej.2017.07.027.

13. Conrado RJ, Gonzalez R. Envisioning the bioconversion of methane to liquid fuels. Science. 2014;343(6171):621-3.

14. Haynes CA, Gonzalez R. Rethinking biological activation of methane and conversion to liquid fuels. Nat Chem Biol. 2014:10:331-9.

15. Kalyuzhnaya MG, Khmelenina VN, Suzina NE, Lysenko AM, Trotsenko YA. New methanotrophic isolates from soda lakes of the southeastern Transbaikal region. Microbiology. 1999;68:677-85.

16. Torre A, Metivier A, Chu F, Laurens LM, Beck DA, Pienkos PT, et al. Genome-scale metabolic reconstructions and theoretical investigation of methane conversion in Methylomicrobium buryatense strain 5G (B1). Microb Cell Fact. 2015;14(1):1.

17. Puri AW, Owen S, Chu F, Chavkin T, Beck DA, Kalyuzhnaya MG, et al. Genetic tools for the industrially promising methanotroph Methylomicrobium buryatense. Appl Environ Microbiol. 2015;81 (5):1775-81.

18. Henard CA, Smith H, Dowe N, Kalyuzhnaya MG, Pienkos PT, Guarnieri MT. Bioconversion of methane to lactate by an obligate methanotrophic bacterium. Sci Rep. 2016;6:21585.

19. Henard CA, Smith HK, Guarnieri MT. Phosphoketolase overexpression increases biomass and lipid yield from methane in an obligate methanotrophic biocatalyst. Metab Eng. 2017;41:152-8

20. Demidenko A, Akberdin IR, Allemann M, Allen EE, Kalyuzhanaya MG. Fatty acid biosynthesis pathways in Methylomicrobium buryatense 5G (B1) Front Microbiol. 2017;7:2167.

21. Dong T, Fei Q, Genelot M, Smith H, Laurens LML, Watson MJ, et al. A novel integrated biorefinery process for diesel fuel blendstock production using lipids from the methanotroph, Methylomicrobium buryatense. Energy Convers Manag. 2017;140:62-70.

22. Gilman A, Laurens L, Puri A, Chu F, Pienkos P, Lidstrom M. Bioreactor performance parameters for an industrially-promising methanotroph Methylomicrobium buryatense 5GB1. Microb Cell Fact. 2015;14(1):1-8.
23. Kaluzhnaya M, Khmelenina V, Eshinimaev B, Suzina N, Nikitin D, Solonin A, et al. Taxonomic characterization of new alkaliphilic and alkali tolerant methanotrophs from soda lakes of the Southeastern Transbaikal region and description of Methylomicrobium buryatense sp. nov. Syst Appl Microbiol. 2001:24(2):166-76.

24. Hamer G, Hedén CG, Carenberg CO. Methane as a carbon substrate for the production of microbial cells. Biotechnol Bioeng. 1967;9(4):499-514

25. Vallenet D, Belda E, Calteau A, Cruveiller S, Engelen S, Lajus A, et al. MicroScope - an integrated microbial resource for the curation and comparative analysis of genomic and metabolic data. Nucleic Acids Res. 2013;41(Database issue):D636-47. https://doi.org/10.1093/nar/gks1194.

26. Gibson DG, Young L, Chuang R-Y, Venter JC, Hutchison CA, Smith HO. Enzymatic assembly of DNA molecules up to several hundred kilobases. Nat Meth. 2009;6(5):343-5.

27. Simon R, Priefer U, Pühler A. A broad host range mobilization system for in vivo genetic engineering: transposon mutagenesis in gram negative bacteria. Nat Biotechnol. 1983;1(9):784-91.

28. Fei Q, Chang HN, Shang L, Choi JDR. Exploring low-cost carbon sources for microbial lipids production by fed-batch cultivation of Cryptococcus albidus. Biotechnol Bioprocess Eng. 2011;16(3):482-7.

29. Laurens LM, Quinn M, Van Wychen S, Templeton DW, Wolfrum EJ. Accurate and reliable quantification of total microalgal fuel potential as fatty acid methyl esters by in situ transesterification. Anal Bioanal Chem. 2012;403(1):167-78.

30. Slivka RM, Chinn MS, Grunden AM. Gasification and synthesis gas fermentation: an alternative route to biofuel production. Biofuels. 2011:2(4):405-19.

31. Munasinghe PC, Khanal SK. Syngas fermentation to biofuel: evaluation of carbon monoxide mass transfer and analytical modeling using a composite hollow fiber (CHF) membrane bioreactor. Bioresour Technol. 2012:122:130-6.

32. Eckert CA, Trinh CT. Biotechnology for biofuel production and optimization. New York: Elsevier; 2016.

33. Stanley SH, Prior SD, Leak DJ, Dalton $\mathrm{H}$. Copper stress underlies the fundamental change in intracellular location of methane mono-oxygenase in methane-oxidizing organisms: studies in batch and continuous cultures. Biotechnol Lett. 1983;5(7):487-92.

34. Khmelenina VN, Kalyuzhnaya MG, Sakharovsky VG, Suzina NE, Trotsenko YA, Gottschalk G. Osmoadaptation in halophilic and alkaliphilic methanotrophs. Arch Microbiol. 1999;172(5):321-9.

35. Gonzalez JE, Bennett RK, Papoutsakis ET, Antoniewicz MR. Methanol assimilation in Escherichia coli is improved by co-utilization of threonine and deletion of leucine-responsive regulatory protein. Metab Eng. 2018;45:67-74. https://doi.org/10.1016/j.ymben.2017.11.015.

36. Gimpel JA, Specht EA, Georgianna DR, Mayfield SP. Advances in microalgae engineering and synthetic biology applications for biofuel production. Curr Opin Chem Biol. 2013;17(3):489-95.

37. Damrow R, Maldener I, Zilliges $Y$. The multiple functions of common microbial carbon polymers, glycogen and PHB, during stress responses in the non-diazotrophic cyanobacterium Synechocystis sp. PCC 6803. Front Microbiol. 2016;7:966

38. Work VH, Radakovits R, Jinkerson RE, Meuser JE, Elliott LG, Vinyard DJ, et al Increased lipid accumulation in the Chlamydomonas reinhardtii sta7-10 starchless isoamylase mutant and increased carbohydrate synthesis in complemented strains. Eukaryot Cell. 2010;9(8):1251-61.

39. M-a Han, S-j Hong, Z-h Kim, B-k Cho, Lee H, H-k Choi, et al. Enhanced production of fatty acids via redirection of carbon flux in marine microalga Tetraselmis sp. J Microbiol Biotechnol. 2018;28(2):267-74.

40. Eshinimaev BT, Khmelenina V, Sakharovskii V, Suzina N, Trotsenko YA. Phys iological, biochemical, and cytological characteristics of a haloalkalitolerant methanotroph grown on methanol. Microbiology. 2002;71(5):512-8.

41. But SY, Khmelenina VN, Reshetnikov AS, Mustakhimov II, Kalyuzhnaya MG, Trotsenko YA. Sucrose metabolism in halotolerant methanotroph Methylomicrobium alcaliphilum 20Z. Arch Microbiol. 2015;197(3):471-80.

42. Hoekman SK, Broch A, Robbins C, Ceniceros E, Natarajan M. Review of biodiesel composition, properties, and specifications. Renew Sustain Energy Rev. 2012;16(1):143-69.

43. Bamgboye A, Hansen A. Prediction of cetane number of biodiesel fuel from the fatty acid methyl ester (FAME) composition. Int Agrophys. 2008;22(1):21. 
44. Fei Q, Wewetzer SJ, Kurosawa K, Rha C, Sinskey AJ. High-cell-density cultivation of an engineered Rhodococcus opacus strain for lipid production via co-fermentation of glucose and xylose. Process Biochem. 2015;50(4):500-6.

45. Yoo C, Jun S-Y, Lee J-Y, Ahn C-Y, Oh H-M. Selection of microalgae for lipid production under high levels carbon dioxide. Bioresour Technol. 2010;101(1, Supplement):S71-4.

46. Toledo-Cervantes A, Morales M, Novelo E, Revah S. Carbon dioxide fixation and lipid storage by Scenedesmus obtusiusculus. Bioresour Technol. 2013;130:652-8
47. Dufossé L. Microbial production of food grade pigments. Food Technol Biotechnol. 2006;44(3):313-23.

48. Fei Q, O'Brien M, Nelson R, Chen X, Lowell A, Dowe N. Enhanced lipid production by Rhodosporidium toruloides using different fed-batch feeding strategies with lignocellulosic hydrolysate as the sole carbon source. Biotechnol Biofuels. 2016;9(1):130.

49. Orgill JJ, Atiyeh HK, Devarapalli M, Phillips JR, Lewis RS, Huhnke RL. A comparison of mass transfer coefficients between trickle-bed, hollow fiber membrane and stirred tank reactors. Bioresour Technol. 2013;133:340-6.
Ready to submit your research? Choose BMC and benefit from:

- fast, convenient online submission

- thorough peer review by experienced researchers in your field

- rapid publication on acceptance

- support for research data, including large and complex data types

- gold Open Access which fosters wider collaboration and increased citations

- maximum visibility for your research: over 100M website views per year

At BMC, research is always in progress.

Learn more biomedcentral.com/submissions 